\title{
Eating and Lifestyle of University Students During the Worldwide Covid-19 Pandemic
}

\section{P. Snopek (Petr Snopek) $)^{1,3}$, J. Bejtkovsky (Jiri Bejtkovsky)2, M. Popovicova (Maria Popovicova) $^{4}$, M. Belovicova (Maria Belovicova) $)^{4,5,6}$}

${ }^{1}$ Tomas Bata University in Zlin, Faculty of Humanities, Department of Original Article

Health Care Sciences, Zlin, CZ.

${ }^{2}$ Tomas Bata University in Zlin, Faculty of Management and Economics,

Department of Management and Marketing, Zlin, CZ.

${ }^{3}$ T. Bata Regional Hospital, Zlin, CZ.

${ }^{4}$ St. Elizabeth University of Health and Social Sciences, Bratislava-teacher, SK.

${ }^{5}$ Internal Clinic for Liver Disease Diagnosis and Treatment, Remedium s. r. o., SK.

${ }^{6}$ Slovak Society of Practical Obesitology (SSPO), Bardejov, SK.

\section{E-mail address:}

snopek@utb.cz

\section{Reprint address:}

Petr Snopek

Tomas Bata University in Zlin

Faculty of Humanities, Department of Health Care Sciences

Stefanikova 5670

76001 Zlin

CZ

Source: Clinical Social Work and Health Intervention

Volume: 12

Issue: 5

Pages: 87 - 94

Cited references: 27

\section{Reviewers:}

Selvaraj Subramaniam

Kuala Lumpur

Zofia Szarota

Pedagogical University of Cracow, PL

\section{Keywords:}

Czech Republic. Global COVID-19 Pandemic. Breakfast. Eating. Body Weight. University Student.

\section{Publisher:}

International Society of Applied Preventive Medicine i-gap

CSWHI 2021; 12(5): 87 - 94; DOI: 10.22359/cswhi_12_5_13 CC Clinical Social Work and Health Intervention

\section{Abstract:}

Objective: The aim of this article was to find whether the global COVID-19 pandemic could affect eating habits in the form of breakfast as the first meal of the day, and whether due to the global COVID-19 pandemic there was a change in body weight in selected university students studying in the Czech Republic. Design: Structured anonymous online questionnaire survey Participans: A total of 628 university students studying in the 
Czech Republic (68.95\% women; $31.05 \%$ men) mostly aged 20 to $29(63.38 \%)$

Methods: Mathematical-statistical methods were used to verify the established research questions, namely Pearson's chisquare test and to investigate the strength of the dependence Cramer's V.

Results and Conclusion: There is a relationship between regular eating habits in the form of breakfast as the first morning meal of a day, before and during COVID-19 and gender and also the biological age of respondents. Furthermore, it was found that there is a statistically significant relationship between the change in body weight during COVID-19 and gender, as well as the biological age of the respondents.

\section{Introduction and Theoretical Background}

The Coronavirus 2019 disease (SARS-CoV2 virus, COVID-19) has caused global disruption in the lives of all pupils and students (Powell et al., 2021). Right after the meeting of the State Security Council, on March 10, 2020, by the means of emergency measures, the Ministry of Health decided to ban the personal presence of pupils and students in education and study processes at Czech primary, secondary and higher vocational schools, universities and other school facilities with effect from March 11, 2020 until further notice in order to prevent the spread of COVID-19 disease (mzcr.cz, 2020). From April 20, 2020, gradually the measures began to be relaxed: first for universities; pupils in the 9th grade of primary schools; graduates; then for the rest of the pupils. Physical attendance in classes was voluntary (msmt.cz, 2020).

The government decided to ban the personal presence of pupils and students in higher, secondary and primary schools on October 12, 2020, effective from October 14, 2020. The schools were to open on November 2, 2020, but the epidemiological situation was still unfavorable, so the government decided the schools would remain closed (msmt.cz, 2020; mzcr.cz, 2020).

On May 24, 2021, all primary and secondary schools as well as universities in the Czech Republic returned to full operation without rotation (msmt.cz, 2020; mzcr.cz, 2020).

All these measures influenced and subsequently also forced to change or adjust the daily lifestyle and eating habits of all pupils and students (Powell et al., 2021).

During the social and physical distancing and subsequent lockdown and global pandemic of COVID-19, not only pupils and students, but the entire population has become accustomed to: less movement; less physical activity; sedentary lifestyle; non-adherence to daily routine habits in healthy lifestyle and eating when compared to what it used to be like before the worldwide COVID-19 pandemic. These factors may ultimately lead to adverse effects on human health, such as: eating disorders; increased body fat and obesity; loss of strength and endurance; to an overall weakening of physiological systems due to restriction of movement; online teaching and working from home (Andreato et al., 2020; Jagim et al., 2020; Pinto et al. 2020).

Nieman (2020) argues that after the end of the global COVID-19 pandemic, there will be a significant demographic shift toward obese, physically inactive, and older population in all countries of the world. As further stated by Boukrim et al. (2021), the worldwide COVID-19 pandemic and the associated strict restrictions and limitations have affected lifestyle, especially dietary behavior and physical activity of the population, and increased the risk of stress, especially in adolescents. This increases the consequent risk of degenerative diseases such as obesity, diabetes, cardiovascular diseases and so on, which can lead to a higher risk of death. Babecka (2020) further adds that, obesity significantly increases morbidity and mortality, it worsens the quality of life and brings serious socio-economic problems. In the European region, obesity is an under-estimated and under-diagnosed public challenge health with rapidly increasing prevalence.

Lana et al. (2020) mentions that a healthy and balanced diet and appropriate daily eating habits 
can contribute to the prevention and treatment of diseases, because proper nutrition plays a dominant role in the development and maintenance of the immune system of not only adolescents and young people. Babecka (2020) states that proper nutrition and a healthy lifestyle will help maintain vitality even in old age and reduce the risk of serious diseases such as cancer, heart and vascular diseases, diabetes, obesity or osteoporosis. Even if someone suffers from one of these diseases, it is usually possible to reduce its negative impact on health by making the right nutrition decisions. However, in this context, Ruiz-Roso et al . (2020) states that during the global COVID19 pandemic, it may have been relatively difficult to purchase quality and fresh food or ingredients, and some food shortages may have occurred.

Fulkerson et al. (2017) or Simmons et al. (2012) state that the global COVID-19 pandemic, lockdown and subsequent measures and restrictions could create: closer contact between family members; increase interest in home cooking which could have a positive but also a negative impact on lifestyle, especially on individual families' diets.

Therefore, as reported by Galli et al. (2020), due to the global COVID-19 pandemic, it is desirable and beneficial to conduct research in the field of lifestyle, especially eating, to prevent eating disorders and unhealthy lifestyle, obesity, cardiovascular diseases. Subsequently, this would internally motivate the population to follow daily eating habits.

Experts in healthy lifestyle, especially in eating, recommend that the diet should be nutritionally varied and rich, not exceeding the daily recommendations for calories, solid fats, sodium or added sugars. In addition, it should provide the recommended daily intake of fruits, vegetables, whole grains and low-fat dairy products (Hiza et al., 2012; Reedy et al., 2010; Sliwa et al., 2016). Hiza et al. (2012) further adds that the lifestyle and especially the diet of the population and its quality is directly affected by: biological age; gender; nationality; ethnic origin; income; the highest level of education attained.

On the other hand, Leech et al. (2015) and Spence (2017) argue that a regular diet is a key aspect of eating habits, and breakfast is considered the most important meal of the day because, among other things, it supports the overall better quality of the diet. Furthermore, when preparing breakfast, it is necessary to think about the combination of foods in meals, where, for example, cereals protect against weight gain (Priebe et al., 2016; Williams, 2014).

In this context, Wesnes et al. (2003) state that skipping breakfast has a very negative impact on cognitive processes, functions and overall performance, especially in pupils and students.

The article focuses on finding whether the global COVID-19 pandemic, lockdown and subsequent measures and restrictions could affect changes in behavior and lifestyle preferences, especially in eating, among selected university students studying in the Czech Republic. This change in behavior and preferences could be related to: closure of university canteens; restaurants; restrictions on services; students' returns home; restrictions on physical activity; social distancing; complete lockdown. The aim of this article was to find out whether the global COVID19 pandemic could affect eating habits in the form of breakfast as the first meal of a day, and whether, due to the global COVID-19 pandemic, there was a change in body weight in selected university students studying in the Czech Republic. The article presents a classical structure, i.e. after stating the theoretical basis, a part focused on defining research goals, methodology and data follows. Subsequently, obtained primary data are presented and a discussion is performed. The last part of the article is a conclusion that summarizes the key aspects of the issue.

\section{Research Objectives, Methodology and Data}

The article focuses on the area of healthy lifestyle, especially on eating, of university students studying in the Czech Republic during the global COVID-19 pandemic, when various measures and restrictions were applied, which were directly related to their eating habits and eating in general. However, the question remains whether these measures have positively or negatively affected the lifestyle of the Czech population. Participation in the research was completely anonymous and voluntary. This article presents only some partial fragments of the ascertained primary information, which are part of the whole complex of discovered facts, data and information. 
The main aim of the research was to determine whether there is a statistically significant relationship between regular eating habits in the form of breakfast as the first morning meal of a day before the global COVID-19 pandemic and during the global COVID-19 pandemic and selected respondent characteristics. A partial goal of the research was to determine whether the global COVID-19 pandemic had an effect on the change in body weight of selected university students studying in the Czech Republic.

Research Question 1: Is there a statistically significant relationship between regular eating habits in the form of breakfast as the first morning meal of a day before the global COVID-19 pandemic and during the global COVID-19 pandemic and the gender of respondents?

Research Question 2: Is there a statistically significant relationship between regular eating habits in the form of breakfast as the first morning meal of a day before the global COVID-19 pandemic and during the global COVID-19 pandemic and the biological age of respondents?

Research question 3: Is there a statistically significant relationship between the change in body weight during the global COVID-19 pandemic and the gender of respondents?

Research question 4: Is there a statistically significant relationship between the change in body weight during the global COVID-19 pandemic and the biological age of respondents?

The research was conducted online through an anonymous structured questionnaire survey, which consisted of several consecutive parts. The research ran from November 2020 to February 2021. A total of 639 respondents, i.e. university students studying in the Czech Republic, took part in the research. However, due to incompletion or ambiguity of some answers in the questionnaire survey, a total of 11 questionnaires were discarded. After this correction, a total of 628 questionnaires were used for the mathematical-statistical methods. Verification of the research hypotheses was performed using Pearson's chi-square test which determines whether there is a relationship between selected statistical features. Usually, the defined significance level is $5 \%$, i.e. 0.05 . If the value of $\mathrm{P}$ is lower than this defined level, the conclusion is to reject the null hypothesis. The obtained primary information and data were then processed using a Mi- crosoft Excel 2013 spreadsheet and using the statistical software IBM SPSS Statistics 23. The research was further based on scientific methods such as induction, deduction, analysis and synthesis.

\section{Results and Discussions}

Table (Table 1) presents the structure of the addressed respondents, i.e. university students studying in the Czech Republic participating in the research.

Table 1 Basic characteristics of the addressed respondents (Own elaboration)

\begin{tabular}{|c|c|c|}
\hline Gender & $\begin{array}{l}\text { Absolute } \\
\text { frequency }\end{array}$ & $\begin{array}{l}\text { Relative } \\
\text { frequency }\end{array}$ \\
\hline Women & 433 & $68.95 \%$ \\
\hline Men & 195 & $31.05 \%$ \\
\hline Total & 628 & $100.00 \%$ \\
\hline $\begin{array}{l}\text { Biological } \\
\text { age }\end{array}$ & $\begin{array}{l}\text { Absolute } \\
\text { frequency }\end{array}$ & $\begin{array}{c}\text { Relative } \\
\text { frequency }\end{array}$ \\
\hline 19 & 67 & $10.67 \%$ \\
\hline $20-29$ & 398 & $63.38 \%$ \\
\hline $30-39$ & 42 & $6.69 \%$ \\
\hline 40 and over & 121 & $19.27 \%$ \\
\hline Total & 628 & $100.00 \%$ \\
\hline $\begin{array}{c}\text { Scientific } \\
\text { field of study }\end{array}$ & $\begin{array}{l}\text { Absolute } \\
\text { frequency }\end{array}$ & $\begin{array}{c}\text { Relative } \\
\text { frequency }\end{array}$ \\
\hline Economics & 313 & $49.84 \%$ \\
\hline Humanities & 255 & $40.61 \%$ \\
\hline Technical study & 39 & $6.21 \%$ \\
\hline Art & 21 & $3.34 \%$ \\
\hline Total & 628 & $100.00 \%$ \\
\hline $\begin{array}{l}\text { Change in } \\
\text { body weight }\end{array}$ & $\begin{array}{l}\text { Absolute } \\
\text { frequency }\end{array}$ & $\begin{array}{l}\text { Relative } \\
\text { frequency }\end{array}$ \\
\hline $\begin{array}{l}\text { No change in } \\
\text { body weight }\end{array}$ & 168 & $26.75 \%$ \\
\hline Weight loss & 77 & $12.26 \%$ \\
\hline Weight gain & 378 & $60.19 \%$ \\
\hline $\begin{array}{l}\text { None of the } \\
\text { stated }\end{array}$ & 5 & $0.80 \%$ \\
\hline Total & 628 & $100.00 \%$ \\
\hline
\end{tabular}


Based on Table 1, it can be said that $68.95 \%$ of women and $31.05 \%$ of men participated in the research. These respondents were mostly aged 20 to 29 years $(63.38 \%)$. The second most represented segment, based on the biological age of the respondents, was the age group $40+$. The classification of respondents according to the field of their study represented a total of four fields, namely economics $(49.84 \%)$, humanities $(40.6 \%)$, technical studies $(6.21 \%)$ and art (3.34\%).

Research Question 1: Is there a statistically significant relationship between regular eating habits in the form of breakfast as the first morning meal of a day before the global COVID-19 pandemic and during the global COVID-19 pandemic and the gender of the respondents?

Pearson's chi-square test was used to verify research Question 1. Mathematical-statistical testing of the defined dependence showed that the p-value is lower than the standard defined significance level (0.05). Thus, in this case, there is a statistically significant relationship between regular eating habits in the form of breakfast as the first morning meal of a day before the global COVID-19 pandemic and during the global COVID-19 pandemic and the gender of the respondents $(\mathrm{X} 2=1.009, \mathrm{df}=3, \mathrm{p}<0.05)$. The strength of the dependence was further investigated using Cramer's V, with its value being 0.399 . It can therefore be said that in this case it is a weak relationship.

Research Question 2: Is there a statistically significant relationship between regular eating habits in the form of breakfast as the first morning meal of a day before the global COVID-19 pandemic and during the global COVID-19 pandemic and the biological age of respondents?

In the case of research Question 2, the presumed dependence was verified by the Pearson chi-square test. The research has shown that the $\mathrm{p}$-value is equal to 0.000 . The null hypothesis is therefore rejected at the significance level of 5 $\%$. Thus, it can be concluded that there is a statistically significant relationship between regular eating habits in the form of breakfast as the first morning meal of a day before the global COVID19 pandemic and during the global COVID-19 pandemic and the biological age of respondents $(\mathrm{X} 2=111.212, \mathrm{df}=9, \mathrm{p}=0.000)$. The strength of the dependence was further investigated using
Cramer's V, with its value being 0.172. It can therefore be said that in this case it is a weak relationship.

Research Question 3: Is there a statistically significant relationship between the change in body weight during the global COVID-19 pandemic and the gender of the respondents?

Pearson's chi-square test was used for mathematical-statistical verification of the defined research Question 3. The research found that in this case the p-value is lower than the usually defined level of significance of $5 \%$, i.e. 0.05 . The $\mathrm{P}$-value for the research question is equal to 0.023 . It can thus be argued that there is a statistically significant relationship between the change in body weight during the global COVID-19 pandemic and the gender of the respondents $(\mathrm{X} 2=9.531, \mathrm{df}=3, \mathrm{p}=0.023)$. The strength of the dependence was further investigated using Cramer's V, with its value being 0.123 . It can therefore be said that in this case it is a weak relationship.

Research Question 4: Is there a statistically significant relationship between the change in body weight during the global COVID-19 pandemic and the biological age of respondents?

To verify research Question 4, the Pearson chi-square test was used, where the p-value is lower than the typically determined significance level of $5 \%$. It can be concluded that there is a statistically significant relationship between the change in body weight during the global COVID19 pandemic and the biological age of the respondents $(\mathrm{X} 2=66.888, \mathrm{df}=9, \mathrm{p}<0.05)$. The strength of the dependence was further investigated using Cramer's V, with its value being 0.188 . It can therefore be said that in this case it is a weak relationship.

It can be said that the lockdown and the subsequent global COVID-19 pandemic apparently caused a change in body weight in the respondents who participated in the research. The research also found that the respondents, i.e. selected university students studying in the Czech Republic, during the global COVID-19 pandemic ate breakfast, especially in the time period from 7.00 AM to 7.59 AM from Monday to Friday. During the weekend, i.e. from Saturday to Sunday, they preferred a time period of $\geq 8.00 \mathrm{AM}$. Thus, it can be concluded that during the global COVID-19 pandemic respondents did not skip 
breakfast as frequently as before the global COVID-19 pandemic.

As the research of Deshmukh-Taskar et al. (2013) and Min et al. (2011) show, skipping breakfast was consistently associated with lower intake of micronutrients, failure to meet the recommended intake of calcium, vitamin A, vitamin $\mathrm{C}$ and magnesium compared to regular breakfast consumers. From their research, Cho et al. (2003) further add that skipping breakfast is not an effective way to manage or reduce one's weight. Based on their research in Morocco, Boukrim et al. (2021) found that more than a quarter of their respondents $(26.4 \%)$ were overweight after the first wave of the global COVID-19 pandemic and $4.7 \%$ were obese. This finding corresponds with our research, where 378 of our respondents $(60.19 \%)$ experienced weight gain during the worldwide COVID-19 pandemic. Boukrim et al. (2021) further argue that weight gain is related to: gender; personal expenditure; stress; low physical activity.

Based on their investigations Mestaghanmi et al. (2021), state that women were more likely to change weight, be overweight and obese. Other findings were made by Ruiz-Roso et al. (2020) who claim that during the global COVID-19 pandemic, respondents' intake of legumes, vegetables and fruits increased significantly whether it was breakfast or not. However, it further presents that a total of $14.0 \%$ of their respondents consumed sweet and fried foods during the global COVID-19 pandemic which may, among other things, ultimately lead to obesity.

\section{Conclusion}

As a result of the global COVID-19 pandemic the whole world was forced to adopt measures and restrictions to prevent the spread of a pandemic that affected all areas. This article examines issues focused on a healthy lifestyle, especially on eating, of university students studying in the Czech Republic. The main aim of the research was to determine whether there is a statistically significant relationship between regular eating habits in the form of breakfast as the first morning meal of a day before the global COVID19 pandemic and during the global COVID-19 pandemic and selected respondent characteristics. A partial goal of the research was to determine whether the global COVID-19 pandemic had an effect on the change in body weight of selected university students studying in the Czech Republic.

Through a literature search on the issue, 4 research questions were defined, which were subsequently verified using mathematical-statistical methods. It was found that there was a statistically significant relationship between regular eating habits in the form of breakfast as the first morning meal of a day before the global COVID19 pandemic and during the global COVID-19 pandemic and the gender of respondents as well as the biological age of the respondents. Furthermore, it was found that there is a statistically significant relationship between the change in body weight during the global COVID-19 pandemic and the gender of respondents, as well as the biological age of the respondents. The research presented in this article has certain limitations, which may include a low number of respondents; respondents were only university students studying in the Czech Republic; the research was carried out only online. Despite these limitations, it can be said that this article brings new facts and information that can be used for further research or interpretation.

\section{References}

1. ANDREATO L V, COIMBRA D R, ANDRADE A (2020) Challenges to Athletes During the Home Confinement Caused by the COVID-19 Pandemic. Strength \& Conditioning Journal; doi: 10.1519/SSC. 0000000000000563.

2. BABECKA J (2020) Overweight and obesity of children and adolescents in Slovakia. Ukraine. The health of the nation. doi: 10 . 24144/2077-6594.1.2020.197495.

3. BABECKA J (2020) The impact of the Mediterranean diet on the health of the individual. In: Proceedings of scientific works. Days of Practical Obesitology and Metabolic Syndrome 16-18 July 2020. ISBN 978-83958245-0-0. EAN 9788395824500.

4. BOUKRIM M, OBTEL M, KASOUATI J, ACHBANI A, RAZINE R (2021) Covid-19 and Confinement: Effect on Weight Load, Physical Activity and Eating Behavior of Higher Education Students in Southern Morocco. Annals of Global Health, 87(1); doi: http://doi.org/10.5334/aogh.3144. 
5. DESHMUKH-TASKAR P R, RADCLIFFE J D, LIU Y, NICKLAS T A (2013) Do Breakfast Skipping and Breakfast Type Affect Energy Intake, Nutrient Intake, Nutrient Adequacy, and Diet Quality in Young Adults? NHANES 1999-2002. Journal of the American College of Nutrition, 29(4), 407-418; doi: https://doi.org/10.1080/07315724.2010. 10719858.

6. FULKERSON J A, FRIEND S, HORNING M, FLATTUM C, DRAXTEN M, NEUMARK-SZTAINER D, GURVICH O, GARWICK A, STORY M, KUBIK M Y (2017) Family Home Food Environment and Nutrition-Related Parent and Child Personal and Behavioral Outcomes of the Healthy Home Offerings via the Mealtime Environment (HOME) Plus Program: A Randomized Controlled Trial. Journal of the Academy of $\mathrm{Nu}$ trition and Dietetics, 118(2), 240-251; doi: https://doi.org/10.1016/j.jand.2017.04.006.

7. GALLI F, REGLERO G, BARTOLINI D, VISIOLI F (2020) Better prepare for the next one. Lifestyle lessons from the COVID-19 pandemic. PharmaNutrition, 12, 100193; doi: https://doi.org/10.1016/j.phanu.2020. 100193.

8. HIZA H A B, CASAVALE K O, GUENTHER P M, DAVIS C A (2012) Diet Quality of Americans Differs by Age, Sex, Race/Ethnicity, Income, and Education Level. Journal of the Academy of Nutrition and Dietetics, 113(2), 297-306; doi: 10.1016/j.jand.2012. 08.011 .

9. CHO S, DIETRICH M, BROWN C J P, CLARK C A, BLOCK G (2003) The Effect of Breakfast Type on Total Daily Energy Intake and Body Mass Index: Results from the Third National Health and Nutrition Examination Survey (NHANES III). Journal of the American College of Nutrition, 22(4), 296302; doi: 10.1080/07315724.2003.10719307.

10. JAGIM A R, LUEDKE J, FITZPATRICK A et al. (2020) The Impact of COVID-19-Related Shutdown Measures on the Training Habits and Perceptions of Athletes in the United States: A Brief Research Report. Frontiers in Sports and Active Living, 2 (623068); doi: 10.3389/fspor.2020.623068.

11. LANA R M, COELHO F C, GOMES M F da C et al. (2020) The novel coronavirus (SARS-
CoV-2) emergency and the role of timely and effective national health surveillance. Cadernos de saude publica, 36: e00019620; doi: 10.1590/0102-311x00019620.

12. LEECH R M, WORSLEY A, TIMPERIO A, MCNAUGHTON S A (2015) Understanding meal patterns: definitions, methodology and impact on nutrient intake and diet quality. Nutrition research reviews, 28(1), 121; doi://doi.org/10.1017/S0954422414000 262.

13. MESTAGHANMI H, LABRIJI A, KEHAILOU F Z, MAHFOUD F Z, BATTAI M, JABARI M, M'TOUGUY I, EL AMRANI S (2019) Relationship between obesity, eating habits and lifestyle in an academic population from Casablanca. American Journal of Innovative Research and Applied Sciences, 9(2), 153-166.

14. MIN C, NOH H, KANG Y S, SIM H J, BAIK H W, SONG W O, YOON J, PARK Y H, JOUNG H (2011) Skipping breakfast is associated with diet quality and metabolic syndrome risk factors of adults. Nutrition Research and Practice, 5(5), 455-463; doi: 10.4162/nrp.2011.5.5.455.

15. MINISTRY OF HEALTH OF THE CZECH REPUBLIC Extraordinary measures of the Ministry of Health prohibit the holding of mass events for more than 100 people and teaching in schools. Available online: https:// www.mzcr.cz/dokumenty/mimoradna-opatreni-ministerstva-zdravotnictvi-zakazuji-konani-hromadnych-akcina_18698_1.html?noredirect.

16. MINISTRY OF EDUCATION, YOUTH AND SPORTS (2020) Updated: Schedule of release in the field of education 2020. Available online: https://www.msmt.cz/harmonogram-uvolnovani-opatreni-v-oblasti-skolstvi.

17. NIEMAN D C (2020) Coronavirus disease2019: a tocsin to our aging, unfit, corpulent, and immunodeficient society. Journal of Sport and Health Science, 9(4), 293-301; doi: 10.1016/j.jshs.2020.05.001.

18. PINTO A J, DUNSTAN D W, OWEN N, BONFA E, GUALANO B (2020) Combating physical inactivity during the COVID-19 pandemic. Nature reviews. Rheumatology, 16(7), 347-348; doi: 10.1038/s41584-0200427-z. 
19. POWELL P K, LAWLER S, DURHAM J, CULLERTON K (2021) The food choices of US university students during COVID-19. Appetite, $\quad 161(1) ; \quad$ doi: 10.1016/j.appet.2021.105130.

20. PRIEBE M G, MCMONAGLE J R (2016) Effects of Ready-to-Eat-Cereals on Key Nutritional and Health Outcomes: A Systematic Review. PLoS One, 17, 11(10):e0164931; doi: 10.1371/journal.pone.0164931.

21. REEDY J, KREBS-SMITH S M (2010) Dietary sources of energy, solid fats, and added sugars among children and adolescents in the United States. Journal of the American Dietetic Association, 110(10), 1477-1484; doi: 10.1016/j.jada.2010.07.010.

22. RUIZ-ROSO M B, PADILHA P D, MANTILLA-ESCALANTE D C, ULLOA N, BRUN P, ACEVEDO-CORREA D, PERES W A F, MARTORELL M, AIRES M T, CARDOSO L D, CARRASCO-MARIN F, PATERNINA-SIERRA K, RODRIGUEZMEZA J E, MONTERO P M, BERNABE G, PAULETTO A, TACI X, VISIOLI F, DAVALOS A (2020) Covid-19 Confinement and Changes of Adolescents Dietary Trends in Italy, Spain, Chile, Colombia and Brazil. $\mathrm{Nu}$ trients, 12(6); doi: 10.3390/nu12061807.

23. SIMMONS D, CHAPMAN G E (2012) The significance of home cooking within families. British Food Journal, 114(8), 11841195.

24. SLIWA S, ANZMAN-FRASCA S, LYNSKEY V, WASHBURN K, ECONOMOS C (2016) Assessing the Availability of Healthier Childrens Meals at Leading Quick-Service and Full-Service Restaurants. Journal of $\mathrm{Nu}$ trition Education and Behavior, 48(4), 242249; doi: https://doi.org/10.1016/j.jneb.2016. 01.004 .

25. SPENCE CH (2017) Breakfast: The most important meal of the day? International Journal of Gastronomy and Food Science, 8, 1-6; doi: https://doi.org/10.1016/j.ijgfs.2017.01. 003.

26. WESNES K A, PINCOCK C, RICHARDSON D, HELM G, HAILS S (2003) Breakfast reduces declines in attention and memory over the morning in schoolchildren. Appetite, 41(3), 329-331; doi: https://doi.org/ 10.1016/j.appet.2003.08.009.
27. WILLIAMS P G (2014) The benefits of breakfast cereal consumption: a systematic review of the evidence base. Advances in nutrition, 15, 5(5)636S-673S; doi: 10.3945/an. 114.006247. 